\title{
The Relationship between Pre-endoscopic Rockall Score and Clinical Course of Patients Presenting with Non-Variceal Upper gastrointestinal Bleeding in the Emergency Department
}

\author{
Acil Serviste Non-varisiyel Üst Gastrointestinal Sistem Kanaması ile Başvuran Hastaların \\ Pre-endoskopik Rockall Skorunun Klinik Seyir ile İlişkisi \\ Şahin İÖ' ${ }^{1}$, Acehan $\mathrm{S}^{2}$, Avcı $\mathrm{A}^{2}$, Gülen $\mathbf{M}^{2}$, Satar $\mathrm{S}^{2}$ \\ 1- Mehmet Akif İnan Eğitim ve Araştırma Hastanesi, Acil Tıp Kliniği, Şanlıurfa, Türkiye. 2- Sağlık Bilimleri Üniversitesi, Adana Şehir \\ Eğitim ve Araştırma Hastanesi, Acil Tıp Kliniği, Adana, Türkiye.
}

\begin{abstract}
Aim: There are several scoring systems used for determining the mortality and surgery need among the patients with gastrointestinal bleeding. Aim of this study is to evaluate the relationship between the preendoscopic Rockall score (PreRS) and clinical outcome of the patients with nonvariceal upper gastrointestinal bleeding admitted to emergency department.

Material and Method: Patients over 18 years of age who admitted to our emergency department due to the nonvariceal upper gastrointestinal bleeding between August 2014 and July 2015 were included in this retrospective study.

Results: A total of 368 patients were included in this study. The mean age of the patients was $63,03 \pm 17,43$ years of age. According to the calculated PreRS $56(15,2 \%)$ of the patients were at low risk group whereas $312(84,8 \%)$ of patients were at high risk group. The ratio of the patients with endoscopic Forrest IIc and III ulcers in the high risk PreRS group was significantly lower than the low risk PreRS group $(p<0,05)$. The ratio of the patients who were accepted to intensive care unit or died at the emergency department in the high risk PreRS group was significantly higher than the low risk PreRS group $(p<0,05)$. The ratio and number of the blood transfusion in the high risk PreRS group was significantly higher than the low risk PreRS group $(p<0,05)$. The ratios of the patients with surgery need, rebleeding, mortality during hospitalization and the length of hospital stay were not significantly different in both low and high risk PreRS groups $(p>0,05)$.

Conclusion: Despite various restrictions, PreRS is helpful for risk stratification of the patients admitted to the emergency department with nonvariceal upper gastrointestinal bleeding but it is not helpfull in predicting the clinical outcome of these patients.

ÖZET

Amaç: Gastrointestinal sistem kanamalarında mortalite ve cerrahiye gidecek hastalartn belirlenmesinde birçok skorlama sistemi kullanılmaktadır. Bu çalışmanın amacı acil servise başvuran akut nonvarisiyel üst gastrointestinal sistem kanamalı hastaların preendoskopik Rockall skoru (PreRS) ile klinik seyri arasindaki ilişkinin değerlendirmektir.

Materyal ve Metod: Ağustos 2014 ve Temmuz 2015 arası acil servisimize başvuran 18 yaş üstü nonvarisiyel üst gastrointestinal sistem kanaması tanısı alan hastalar retrospektif olarak çalışmaya dahil edildi.

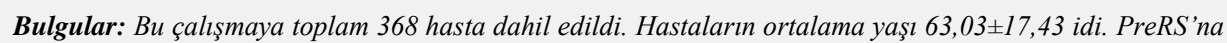
göre hastaları 56 'sı $(\%$ 15,2) düşük riskli, 312 'si $(\%$ 84,8) yüksek riskli grupta idi. PreRS yüksek riskli olan grupta endoskopik Forrest IIc ve III olan hasta oranı PreRS düşük riskli olan gruptan anlaml $(p<0,05)$ olarak düşük bulundu. Hastaların yoğun bakım yatışı ve acilde exitus oranı PreRS yüksek riskli olan grupta PreRS düşük risk olan gruptan anlamlı $(p<0,05)$ olarak daha yüksek bulundu. PreRS yüksek risk olan grupta kan transfüzyon yapılma oranı ve saylsı PreRS düsük risk olan gruptan anlamlı $(p<0,05)$ olarak daha yüksek bulundu. PreRS düşük ve yüksek olan grupta cerrahi geçirme, tekrar kanama, yatıșta exitus oranları ve yatış süresi anlamlı $(p>0,05)$ farklllik saptanmadl.

Sonuç: Çeşitli kısıtlılıkları olmasına karşın acil servise başvuran NVÜGK'lı hastaların risk sınıflamasının yapılmasında PreRS faydalı olduğu, ancak seyrin öngörülmesinde yardımcı olmayabileceği söylenebilir.
\end{abstract}

Key Words:

Emergency Department,

Upper Gastrointestinal Bleeding,

Pre-endoscopic Rockall Score.

Anahtar Kelimeler:

Acil Servis,

Gastrointestinal Kanama,

Preendoskopik Rockall skoru.

\section{Giriș}

Gastrointestinal sistem (GIS) kanamaları Amerika Birleşik Devletleri'nde (ABD) yılda yaklaşık bir milyonun üzerinde hastaneye yatışa yol açmakta ve ciddi morbidite, mortalite ve ekonomik yükü beraberinde getirmektedir (1). Treitz ligamanının proksimalindeki kanamalar üst GİS kanamaları,

distalindeki kanamalar ise alt Gís kanamaları olarak sınıflandırılmaktadır. Üst Gís kanamaları ABD'de her y1l yaklaşı 500.000 'den fazla hastaneye yatışa yol açmaktadır ve yaklaşık olarak 100.000 hastada 165 insidansa sahiptir. ABD'de alt GİS kanamalarının insidansı ise yaklaşı olarak 100.000 hastada 20,5 ve

Correspondence: Akkan Avcı, MD, Sağlık Bilimleri Üniversitesi, Adana Şehir Eğitim ve Araştırma Hastanesi, Acil Tıp Kliniği, Adana, Türkiye. E-mail: drakkanavci@gmail.com Phone : +90 5334230369

Cite this article as: Şahin İ̈, Acehan S, Avcı A, Gülen M, Satar S. The Relationship between Pre-endoscopic Rockall Score and Clinical Course of Patients Presenting with Non-Variceal Upper gastrointestinal Bleeding in the Emergency Department. Phnx Med J. 2019; 1(1): 1-7. 
mortalitesi \% 4'tür (2). Üst GİS kanamaları genellikle tüm GİS kanamalarının \% 85'ini oluşturmaktadır. Bu kanamaların da \% 70-80'i kendiliğinden durur $(3,4,5)$. 1957'de fleksibl endoskopinin kullanıma girmesi, üst gastrointestinal sistem kanamalarında tanı ve tedavi yaklaşımlarını köklü bir değişikliğe uğratmıştır. Endoskopinin tanı ve tedavide kullanımından önceki dönemlerde körlemesine yapılan cerrahi girişimler artık geride kalmıştır. Üst GİS kanamalarında mortalite ve cerrahiye gidecek hastaları önceden belirleyen birçok skorlama sistemleri vardir.

Biz bu çalışmamızda acil servisimize nonvarisiyel üst gastrointestinal sistem kanaması (NVÜGK) ile başvuran hastaların demografik ve klinik özelliklerin Rockall skorlama (RS) yöntemi kullanılarak değerlendirilmesini ve preendoskopik Rockall skoru ile klinik seyir arasındaki ilişkinin belirlenmesini amaçladik.

\section{MATERYAL VE METOD}

Adana Numune Eğitim ve Araştırma Hastanesi Acil Tip Kliniği'ne 01 Ağustos 2014 ile 31 Temmuz 2015 tarihleri arasında başvuran 18 yaş üstü non-varisiyel üst GİS kanamalı (NVÜGK) 368 hasta dahil edildi. Çalışmaya etik kurul onayı alındıktan sonra başlandı. Acil servisimize hematemez, melena, hematokezya gibi GİS kanama belirtileri ve kanlı kusma, kanlı dışkılama, siyah dişkılama şeklinde şikayetlerle başvuran hastalardan acil servis muayene kartlarına ulaşılabilenler değerlendirmeye alındı. Alınan anamnez, yapılan fizik muayene ve endoskopi sonucu ile NVÜGK tanısı konulan hastalar çalışmaya dahil edildi.

\section{Hastaların Seçimi ve Grupların Oluşumu}

Çalışmaya dahil edilen hastaların değerlendirilmesinde kullanılan çalışma formunda hastaların yaşı, cinsiyeti, ilaç kullanım öyküsü, GİS kanama öyküsü, başvuruda melena varlığ 1 , başvuru sırasındaki nabız ve tansiyon değerlerine göre şok durumu, sahip olduğu komorbid hastalıklar, Forrest siniflamasi, hesaplanan preendoskopik ve postendoskopik Rockall skoru, ilk 24 saatte yapılan eritrosit suspansiyonu transfüzyonu sayısı, hastaların sonlanım durumları, yatışı yapılan hastaların tekrar kanama veya cerrahi geçirip geçirmedikleri, yatış sonucu, yattıkları gün sayısı ve acil servise başvuruları sırasındaki laboratuar değerleri tespit edilerek kayıt altına alındı.

Hastaların yaşı $<60,60-79$ ve $\geq 80$ yaş olarak üç grupta değerlendirildi. Hastaların kullandığı ilaçlar sorgulanarak GİS kanama ile ilişkili olabileceği gösterilmiş olan asetilsalisilik asit (ASA), nonsteroid antiinflamatuar ilaçlar (NSAIII), varfarin sodyum, klopidogrel ve diğer antikoagulan veya antiagregan ilaçlar olmak üzere beş grupta toplandi. Acil servise başvuru sırasındaki vital bulgularından nabız ve kan basınc1 değerleri şok durumunun belirlenmesinde kullanıld 1 ve hipotansif hastalar (kan basinc1 $<100 \mathrm{mmHg}$ ), taşikardik hastalar (nabız $\geq 100$ /dakika ve kan basıncı $\geq 100 \mathrm{mmHg}$ ) ve şok olmayan hastalar (nabız $<100 /$ dakika ve kan basinc $\geq 100 \mathrm{mmHg}$ ) olarak üç gruba ayrıldı. Komorbid hastalıklar ise kalp yetmezliği, iskemik kalp hastalığı, böbrek yetmezliği, karaciğer yetmezliği, metastatik kanser hastalığı olarak grupland1. Endoskopisi yapılan hastaların endoskopi sonuçları normal olan, Mallory Weiss tespit edilen, GİS malignensi tespit edilen hastalar ve diğer malignensi dışı nedenler olmak üzere dört ana grup altında toplandi. Endoskopi sonucu malignensi dışı tespit edilen diğer nedenler ise peptik ülser hastalığ (özofagus, mide ve duodenum ülseri), özofajit, gastrit (gastropati), duodenit, intestinal metaplazi, Schatzki halkası, hiyatal herni, anjiyodisplazi, kameron ülseri, polip, lipom, Dieulafoy lezyonu, midede bezoar, gastrointestinal obstruksiyon ve divertikül olarak çalışma formuna kaydedildi. Acil serviste veya yatışı yapıldıktan sonra gerek hastanın exitus olması gerek hastanın tolore edememesi ve diğer nedenlerle endoskopisi yapılamayan hastalar bu şekilde endoskopisi yapılmamış veya yapılamamış hastalar olarak kayıt altına alındı. Endoskopi sonucu ülser tespit edilen hastalar Forrest sinıflamasına göre gruplandi.

Hastaların yaşı, şok durumu ve komorbid hastalıkları değerlendirmeye alınarak PreRS ve endoskopisi yapilan hastalarda Tam Rockall Skoru (TRS) hesaplanarak kaydedildi. Acil servisten taburcu edilen, acil serviste exitus olan, yatışı servise veya yoğunbakıma yapılan hastalar kayıt altına alınarak hastaların acil serviste nasıl sonuçlandırıldığı belirlendi. Yatışı yapılan hastaların yatış sonucu, taburculuk ve exitus olmak üzere belirlendi. Her hastanın acil servise başvuru sırasındaki hemoglobin, hematokrit, trombosit, ortalama eritrosit hacmi (MCV), üre, kreatinin, alanin aminotransferaz (ALT), aspartat aminotransferaz (AST), protrombin zamanı (PTZ), Aktive Parsiyel Tromboplastin Zamanı (aPTT), international normalized ratio (INR) değerleri bulunarak çalışma formuna kaydedildi.

Hastalar PreRS'na göre 0 puan aldıkları takdirde düşük riskli, 1 ve üzeri puan aldıkları takdirde yüksek riskli olarak gruplandı. Çalışmamızda yer alan 368 hastadan 23'üne endoskopi uygulanamadığından TRS hesaplanabilen hastalar ise aldıkları puan 0-2 arası olanlar düşük riskli, 3-4 olanlar orta riskli, 5 ve 5'in üstü puan alanlar yüksek riskli olarak grupland. PreRS'na göre düşük ve yüksek riskli olan gruplar hastaların klinik seyrini belirleyen yoğun bakım yatışı, eksitus, tekrar kanama, cerrahi geçirme oranları, gün olarak yatış süresi, kan transfuzyonu ihtiyacı ve endoskopisinde ülser tespit edilen hastalarda endoskopik Forrest sınıfıyla ilişskilendirildi. Çoğunlukla endoskopik müdahaleyi gerektiren ve tekrar kanama oranları yüksek olan Forrest Ia, Ib, IIa, IIb lezyonlar yüksek riskli grup, çoğunlukla endoskopik tedavi uygulanmayan Forrest IIc ve III lezyonlar düşük riskli grup olarak değerlendirmeye alındı. Forrest sinıflamasina göre birden fazla sınıf ülseri olan hastalarda istatistiksel analiz sırasında şiddeti yüksek olan Forrest sınıfı esas alındı. 
Tablo 1. Hastaların ilk başvuru sırasındaki kan sonuçları

\begin{tabular}{llllll}
\hline Kan testi adı & $\begin{array}{l}\text { Referans } \\
\text { aralık }\end{array}$ & Birim & Min.-mak. & Med. & Ort \pm s.s. \\
\hline Hemoglobin & $10,6-13,5$ & $\mathrm{~g} / \mathrm{dL}$ & $3,6-18,4$ & 9,5 & $9,5 \pm 2,8$ \\
\hline Hematokrit & $32,9-41,2$ & $\%$ & $10,9-56,1$ & 28,3 & $28,7 \pm 8,5$ \\
\hline Trombosit & $186-353$ & $\mathrm{x} 1000 / \mu \mathrm{L}$ & $7-771$ & 246 & $261,8 \pm 97,9$ \\
\hline MCV & $77,7-93,7$ & $\mathrm{fL}$ & $62,8-124,0$ & 87,9 & $87,5 \pm 6,9$ \\
\hline Üre & $16,6-48,5$ & $\mathrm{mg} / \mathrm{dL}$ & $13,0-365,0$ & 70,0 & $84,1 \pm 54,7$ \\
\hline Kreatinin & $0,5-0,9$ & $\mathrm{mg} / \mathrm{dL}$ & $0,4-10,5$ & 1,0 & $1,4 \pm 1,4$ \\
\hline ALT & $0-33$ & $\mathrm{U} / \mathrm{L}$ & $5,0-1092,0$ & 14 & $25,4 \pm 65,5$ \\
\hline AST & $0-32$ & $\mathrm{U} / \mathrm{L}$ & $4,0-2232,0$ & 20,0 & $38,9 \pm 128,6$ \\
\hline PTZ & $10-14$ & saniye & $10,2-204,8$ & 13,1 & $20,7 \pm 28,6$ \\
\hline aPTT & $21-36$ & saniye & $16,9-140,4$ & 23,6 & $30,2 \pm 20,9$ \\
\hline INR & $0,8-1,2$ & & $0,9-10,0$ & 1,1 & $1,5 \pm 1,5$ \\
\hline
\end{tabular}

\section{Ístatistiksel Analiz}

Çalışmamız sırasında kullandığımız istatistiksel yöntemde verilerin tanımlayıcı istatistiklerinde ortalama, standart sapma, medyan, en düşük, en yüksek, frekans ve oran değerleri kullanıldı. Analizlerde SPSS 22.0 programı kullanıldı. Değişkenlerin dağılımı Kolmogorov-Simirnov testi ile ölçüldü. Nicel verilerin analizinde Mann-Whitney U test kullanıldı. Nitel verilerin analizinde ise ki-kare test ki-kare test koşulları sağlanmadığında Fischer test kullanıldı.

\section{BULGULAR}

Çalışmamıza acil servisimize başvuran NVÜGK'l1 368 hasta dahil edildi. Başvuran hastaların cinsiyet dağılımına bakıldığında hastaların 237'si erkek (\% 64,4) ve 131'i kadın $(\% 35,6)$ idi. Yaş dağılımına bakıldığında ise hastaların 144'ü 60 yaş altı (\% 39,13), 158 'i $60-79$ yaş arasında (\% 42,94), 66'sı ise 80 yaş ve üzeri $(\%$ 17,93) olarak tespit edildi. Hastaların yaş ortalaması 63,03 $\pm 17,43$ olarak hesapland. Acil servise başvuru sırasında hastalardan alınan kan sonuçları Tablo 1'de gösterilmiştir.

Çalışmaya alınan hastaların ilaç kullanım öyküleri sorgulandığında bazı hastalar birden fazla grup ilaç kullanmaktaydı ve 127 hastanın (\% 34,5) hiçbir ilaç kullanım öyküsü mevcut değildi. Çalışmamızdaki 102 hasta $(\%$ 27,7) NSAİI, 121 hasta $(\% 32,9)$ ASA, 37 hasta (\% 10,1) varfarin sodyum, 20 hasta (\% 5,4) klopidogrel ve 15 hasta $(\% 4,1)$ diğer antiagregan veya antikoagulan ilaçlardan kullanmaktaydı. Çalışmamızda NVÜGK ile başvuran hastaların \% 65,5'inde GISS kanama ile ilişsilendirilebilecek türde ilaç kullanımı mevcuttu.

Çalışmamızdaki hastaların 70'inde $(\%$ 19,0) daha önceden GİS kanama öyküsü saptanmış olup, hastaların 267 'sinde $(\% 72,6)$ acil servise başvurundaki fizik muayenesinde melena tespit edildi.

Hastaların 96'sının (\% 26,1) hipotansiyon ile acil servise başvurduğu ve kan basınçlarının $<100$ mm-Hg
Tablo 2. Hastaların endoskopi sonuçları

\begin{tabular}{|c|c|c|}
\hline Endoskopik tanı & $\begin{array}{c}\text { Sayı } \\
\text { n }\end{array}$ & $\begin{array}{c}\text { Yüzde } \\
(\%)\end{array}$ \\
\hline Normal & 48 & 13,9 \\
\hline Mallory Weiss & 4 & 1,1 \\
\hline GİS malignensi & 23 & 6,7 \\
\hline Özafagusta ülser & 28 & 8,1 \\
\hline Midede ülser & 105 & 30,4 \\
\hline Duodenal ülser & 145 & 42,0 \\
\hline Özofajit & 53 & 15,4 \\
\hline Gastrit & 125 & 36,2 \\
\hline Duodenit & 49 & 14,2 \\
\hline Kanama dışı diğer nedenler & 73 & 21,2 \\
\hline $\begin{array}{ll} & \text { Hiyatal herni }\end{array}$ & 47 & 13,6 \\
\hline - $\quad$ Polip & 6 & 1,7 \\
\hline - $\quad$ İntestinal metaplazi & 5 & 1,5 \\
\hline - Schatzki halkası & 5 & 1,5 \\
\hline - $\quad$ Enterogastrik reflü & 5 & 1,5 \\
\hline - $\quad$ Divertikül & 2 & 0,5 \\
\hline - $\quad$ Lipom & 1 & 0,3 \\
\hline - $\quad$ Midede bezoar & 1 & 0,3 \\
\hline - $\quad$ GİS obstrüksiyonu & 1 & 0,3 \\
\hline $\begin{array}{llll}\text { Kanamaya yol açan diğer } \\
\text { nedenler }\end{array}$ & 8 & 2,3 \\
\hline • $\quad$ Anjiyodisplazi & 3 & 0,9 \\
\hline • $\quad$ Kameron ülseri & 3 & 0,9 \\
\hline - Dieulafoy lezyonu & 2 & 0,5 \\
\hline
\end{tabular}

olduğu tespit edilirken, 113 'ünde (\% 30,7) taşikardi saptand1. 159 hastada (\% 43,2) ise şok bulgusu gözlenmedi. 
Tablo 3. Hastaların hesaplanan Rockall skorları

\begin{tabular}{|c|c|c|c|c|c|c|}
\hline & & Min-Mak & Med & Ort. \pm s.s. & $\mathbf{n}$ & $\%$ \\
\hline Preendoskopik rockall skoru & & $0,0-7,0$ & 3,0 & $2,9 \pm 1,9$ & & \\
\hline \multirow{2}{*}{$\begin{array}{l}\text { Preendoskopik rockall } \\
\text { skoru }\end{array}$} & Düşük Risk & & & & 56 & 15,2 \\
\hline & Yüksek Risk & & & & 312 & 84,8 \\
\hline Preendoskopik rockall skoru & & $0,0-10,0$ & 5,0 & $4,5 \pm 2,3$ & & \\
\hline \multirow{3}{*}{$\begin{array}{l}\text { Preendoskopik rockall } \\
\text { skoru }\end{array}$} & Düşük Risk & & & & 86 & 23,4 \\
\hline & Orta Risk & & & & 86 & 23,4 \\
\hline & Yüksek Risk & & & & 273 & 47,0 \\
\hline
\end{tabular}

Çalışmamızda yer alan 368 hastanın 23'üne (\% 6,3) endoskopi yapılamadığı tespit edildi. Endoskopisi yapılan 345 hastanın sonuçları incelendiğinde hastaların 48 'inde $\left(\begin{array}{lll}\% & 13,9\end{array}\right)$ endoskopi bulguları normalken, 105 'inde $(\% 30,4)$ mide ülseri, 125 'inde (\% 36,2 ) gastrit ve 145 'inde (\% 42,0) duodenal ülser tespit edildi (Tablo 2).

Çalışmaya katılan hastaların PreRS'ları ve endoskopisi yapılan hastalarda TRS'ları tablo 3'te gösterilmiştir.

Hastalarda görülen ülserlerin endoskopik Forrest sinıflamasına göre 6'sında (\% 2,6) Forrest Ia, 32'sinde $(\%$ 13,8) Forrest Ib, 36'sinda (\% 15,5) Forrest IIa, 24'ünde (\% 10.3) Forrest IIb, 9'unda (\%3.9) Forrest IIc, ve 125 'inde (\% 53.9) Forrest III ülser tespit edildi (Tablo 4).

Endoskopi sonucu Forrest IIc ve III ülser tespit edilen 134 hastanın 1'i $(\% 0,7)$ acilden taburcu edildi. 46's1 $\left(\begin{array}{l}\% \\ \%\end{array} 34,3\right)$ servise, 87'si (\% 65) ise yoğun bakım ünitesine yatırıldı. Yatırılan hastalardan 132'si taburcu olurken 1'i exitus olduğu tespit edildi. Bu hastaların 76'sına (\% 56,7) ilk 24 saatte kan transfüzyonu yapıldı ̆̆ ve ortalama 2,3 ünite ES transfüzyonu uygulandığı saptandı. Yatışı yapılan 133 hastanın 2'sinde tekrar kanama, 2'sinde ise cerrahi girişim ihtiyacı olduğu saptandı. Hastaların ortalama yatış gün sayıs1 4,7 gün idi.

Endoskopi sonucu Forrest Ia, Ib, IIa ve IIb ülser tespit edilen 98 hastanın 14'ü (\% 14,3) servise, 84'ü (\% 86) ise yoğun bakıma yatırıldığı takip sonrası hastaların 91'i taburcu edildiği, 7'sinin ise exitus olduğu saptandi. Hastaların 70'ine (\% 71) ilk 24 saatte kan transfüzyonu yapıldığı ve ortalama 2,6 ünite ES transfüzyonu

Tablo 4. Ülser tespit edilen hastalarda endoskopik Forrest sınıflamasına göre dağılım

\begin{tabular}{lll}
\hline $\begin{array}{l}\text { Endoskopik } \\
\text { sinıflaması }\end{array}$ & Sorrest & $\begin{array}{l}\text { Yüzde } \\
\text { (\%) }\end{array}$ \\
\hline Ia & 6 & 2,6 \\
\hline Ib & 32 & 13,8 \\
\hline IIa & 36 & 15,5 \\
\hline IIb & 24 & 10,3 \\
\hline IIc & 9 & 3,9 \\
\hline III & 125 & 53,9
\end{tabular}

uygulandığ 1 saptandı. Hastaların 12'sinde tekrar kanama geliştiği, 4'ünde ise cerrahi girişim ihtiyacı olduğu saptandı. Hastaların ortalama yatış gün sayısı ise 6,3 gün idi.

Çalışmamızdaki NVÜGK tanısı alan 368 hastanın 11 'inin $(\% 3,0)$ acilden taburcu edildi, 2'sinin (\% 0,5) acilde exitus olduğu, 103 'ünün (\% 28,0) servise yattığ 1 , kalan 252'nin $(\% 68,5)$ ise yoğun bakım ünitesine alındığ 1 tespit edildi.

İlk 24 saat içerisinde çalışmada yer alan 368 hastanın 153’üne (\% 41,6) hiç eritrosit suspansiyonu (ES) transfüzyonu yapılmadığı, kalan 215 hastaya $(\% 58,4)$ transfüzyon yapıldı̆̆

Çalışmaya dahil edilen hastaların 16'sında (\% 4,3) tekrar GİS kanama geliştiği, 9'unun $(\% 2,4)$ ise cerrahi tedavi aldığ 1 tespit edildi.

PreRS ile Forrest sınıflamasının ilişkisi analiz edilirken birden fazla sınıf ülseri olan hastalarda derecesi ve şiddeti yüksek olan Forrest sınıfı esas alındı. Örneğin hem IIa hem IIc ülseri olan bir hastada istatistiksel analiz açısından IIa ülser esas alındı. Ülserler ise Forrest sınıflamasına göre çoğunlukla endoskopik tedavi gerektiren ve tekrar kanama riski yüksek olan Ia, Ib, IIa, IIb ve düşük riskli IIc ve III olmak üzere ikiye grupland1. Ki-kare testi kullanılarak yapılan istatistiksel analiz sonucu PreRS yüksek risk olan grupta endoskopik forest IIc-III olan hasta oranı Preendoskopik Rocall Skoru düşük risk olan gruptan anlamlı $(\mathrm{p}<0,05)$ olarak daha düşük bulundu (Tablo 5).

PreRS yüksek risk olan grupta yoğun bakıma yatıs ve acilde exitus oranı PreRS düşük risk olan gruptan anlamlı $(\mathrm{p}<0,05)$ olarak daha yüksek bulguland1. PreRS düşük ve yüksek olan grupta cerrahi geçirme oranı, yatış günü, yatışta exitus oranı anlamlı $(\mathrm{p}>0,05)$ farklılık göstermemiştir (Tablo 6).

PreRS yüksek risk olan grupta kan transfüzyon yapılma oranı ve sayısı PreRS düşük risk olan gruptan anlamlı $(\mathrm{p}<0,05)$ olarak daha yüksektir. PreRS düşük ve yüksek olan grupta tekrar kanama oranı anlamlı ( $p>$ 0,05 ) farklılık göstermemiştir (Tablo 7). 
Tablo 5. PreRS ile Endoskopik Forrest Arasındaki İlişki

\begin{tabular}{|c|c|c|c|c|c|c|}
\hline & & \multicolumn{4}{|c|}{ Preendoskopik rockall skoru } & \multirow{3}{*}{$\mathbf{p}$} \\
\hline & & \multicolumn{2}{|c|}{ Düşük Risk } & \multicolumn{2}{|c|}{ Yüksek Risk } & \\
\hline & & $\mathbf{n}$ & $\%$ & $\mathbf{n}$ & $\%$ & \\
\hline \multirow{6}{*}{ Endoskopik Forrest } & Ia & 2 & $\% 5,7$ & 4 & $\% 2,0$ & \multirow{6}{*}{0,032} \\
\hline & Ib & 5 & $\% 14,3$ & 27 & $\% 13,7$ & \\
\hline & IIa & 1 & $\% 2,9$ & 35 & $\% 17,8$ & \\
\hline & IIb & 1 & $\% 2,9$ & 23 & $\% 11,7$ & \\
\hline & IIc & 2 & $\% 5,7$ & 7 & $\% 3,6$ & \\
\hline & III & 24 & $\% 68,6$ & 101 & $\% 51,3$ & \\
\hline
\end{tabular}

Ki-kare test

Tablo 6. PreRS ile Hastaların Yoğun Bakıma Yatış, Yatış Sonucu, Yatış Süresi ve Cerrahi Geçirme Arasındaki İlişki

\begin{tabular}{|c|c|c|c|c|c|c|c|c|c|c|}
\hline & \multicolumn{7}{|c|}{ Preendoskopik rockall skoru } & & \multirow{3}{*}{$\mathbf{p}$} \\
\hline & & \multicolumn{4}{|c|}{ Düşük Risk } & \multicolumn{4}{|c|}{ Yüksek Risk } & \\
\hline & & Ort. \pm s.s. & n & $\%$ & Med & Ort. \pm s.s. & $\mathbf{n}$ & $\%$ & Med & \\
\hline \multirow{4}{*}{$\begin{array}{l}\text { Hastanın } \\
\text { Sonucu }\end{array}$} & $\begin{array}{l}\text { Acilden } \\
\text { taburcu }\end{array}$ & & 6 & $\% 10,7$ & & & 6 & 1,9 & & \multirow{4}{*}{0,00} \\
\hline & Servise Yatış & & 26 & $\% 46,4$ & & & 76 & 24,4 & & \\
\hline & YB Yatt1 & & 24 & $\% 42,9$ & & & 228 & 73,1 & & \\
\hline & Acilde Eksitus & & 0 & $\% 0,0$ & & & 2 & 0,6 & & \\
\hline \multirow{2}{*}{$\begin{array}{l}\text { Cerrahi } \\
\text { Geçirme }\end{array}$} & Yok & & 54 & $\% 96,4$ & & & 305 & 97,8 & & \multirow{2}{*}{0,631} \\
\hline & Var & & 2 & $\% 3,6$ & & & 7 & 2,2 & & \\
\hline Yatış Günü & & $4,2 \pm 5,6$ & & & 3 & $5,1 \pm 5,5$ & & & 4 & 0,056 \\
\hline \multirow{2}{*}{ Yatış Sonucu } & Taburcu & & 50 & $\% 100$ & & & 285 & 93,4 & & \multirow{2}{*}{0,062} \\
\hline & Exitus & & 0 & $\% 0$ & & & 20 & 6,6 & & \\
\hline
\end{tabular}

Ki-kare test (Fischer test ) / Mann-whitney u test

Tablo 7. PreRS ile kan transfüzyonu ve tekrar kanama arası ilişki

Preendoskopik rockall skoru

\begin{tabular}{|c|c|c|c|c|c|c|c|c|c|c|}
\hline & \multirow{2}{*}{\multicolumn{4}{|c|}{ Düşük Risk }} & \multirow{2}{*}{\multicolumn{4}{|c|}{ Yüksek Risk }} & \multirow{3}{*}{$\mathbf{p}$} \\
\hline & & & & & & & & & & \\
\hline & & Ort. \pm s.s. & $\mathbf{n}$ & $\%$ & Med & Ort. \pm s.s. & $\mathbf{n}$ & o & Med & \\
\hline \multicolumn{2}{|c|}{ Kan (E.S.) Transfüzyonu } & $0,2 \pm 0,5$ & & & 0 & $1,7 \pm 1,5$ & & & 2 & 0,000 \\
\hline \multirow{2}{*}{$\begin{array}{l}\text { Kan (E.S.) } \\
\text { Transfüzyonu }\end{array}$} & Yapılmadi & & 49 & 87,5 & & & 104 & 33,3 & & \multirow{2}{*}{0,000} \\
\hline & Yap1ld 1 & & 7 & 12,5 & & & 208 & 66,7 & & \\
\hline \multirow{2}{*}{ Tekrar Kanama } & Yok & & 55 & 98,2 & & & 297 & 95,2 & & \multirow{2}{*}{0,307} \\
\hline & Var & & 1 & 1,8 & & & 15 & 4,8 & & \\
\hline
\end{tabular}

Ki-kare test / Mann-whitney u test 


\section{TARTISSMA}

Nonvarisiyel üst gastrointestinal sistem kanamaları (NVÜGK) sık görülen, mortalite ve morbidite oranı yüksek önemli bir acildir. H2 reseptör antagonisti (H2RA) ve proton pompa inhibitörü (PPİ) gibi ilaçların ve endoskopinin geliştirilmesi sayesinde önceleri körlemesine yapılan cerrahi girişimler artık geride kalmıştır. Helikobacter pylori enfeksiyonunun peptik ülser gelişimi üzerindeki etkisinin anlaşılmasıyla birlikte eradikasyon tedavisinin bulunması peptik ülsere bağlı GİS kanama oranlarında azalmaya yol açmıştır. Tüm bu gelişmelere karşın mortalite oranı halen \% 10 seviyelerinde kalmıştır ${ }^{6}$.

NVÜGK ile acil servise başvuran hastaların hızlı bir şekilde değerlendirilip uygun triyaj yapılması, risk seviyelerinin erkenden belirlenmesi bu şekilde tetkik ve tedavi süreçlerinde doğru ve hızlı karar verilmesi hastalığın gidişatı, kaynakların kullanımı ve maliyet açısından olumlu sonuçlar doğurabilecektir ${ }^{7}$. NVÜGK ile başvuran hastaların risk sınıflamasının yapılıp ayaktan veya yatarak takip edilecek olanları belirlemek için çeşitli risk skorlama sistemleri geliştirilmiştir ${ }^{8}$. Bu skorlama sistemleri arasında Rockall Skoru (RS) İngiltere'de 74 hastaneye üst GİS kanaması nedeniyle başvuran 4185 hastayı içeren çok merkezli bir çalışma ile ortaya konulmuş olup daha sonra 1625 vakalık ikinci grup hasta ile skorlama sisteminin uygulanabilirliği araştırılmıştır. RS diğer skorlama sistemlerine kiyasla uluslararası güvenilirlik testi yapılmış tek skorlama sistemidir. Rockall skorlama sistemi ile yüksek risk grubunda olup yakın takip gerektiren ve düşük risk grubunda olup erken taburculuğu yapılabilecek hastalar belirlenebilmekte, tekrar kanama ve mortalite için düşük riskli hastaların $\%$ 15'ini başvuru anında\% 26'sını ise endoskopi sonrası belirleyebilmektedir ${ }^{6}$. RS 2 ve düşük olan hastalarda tekrar kanama oranı $\% 4$, mortalite oranı ise $\% 0,1$ olarak belirlenmiştir ${ }^{9}$.

Çalışmamız sonucunda erkek ve kadın hastaların oranı literatür ile benzerlik göstermekte olup hastaların \% 64,4'ü erkek \% 35,6's1 ise kadındıve ortalaması $63,03 \pm 17,43$ idi. Ferhat ve arkadaşlarının 2011'de yaptığı benzer bir çalışmada da aynı sonuçlar bulunmuştur ${ }^{7}$. Genellikle üst GİS kanamalarının erkeklerde kadınlardan yaklaşık 2 kat fazla görüldüğü kabul edilmekte olup bu durumu destekleyen birçok çalışma mevcuttur $8,9,11$.

Üst GİS kanamalı hastaların acil servise en sık başvuru şekli melena olup bizim çalışmamızda bu oran \% 72,6 olarak bulunmuştur. Hastaların melena ile başvuru oranı Wang ve arkadaşları tarafından yapılan çalışmada $\%$ 82,1, Işık ve arkadaşlarının yaptığı çalışmada \% 76,1 , Dicu ve arkadaşlarının yaptığı çalışmada ise \% 70,7 olarak bulunmuştur ${ }^{10-12}$. Bir diğer çalışmada NVÜGK hastaların \% 79,4'ünde melena tespit edilmiştir $^{13}$. Bu veriler 1 şığında çalışmamız sonucunda literatür ile uyumlu sonuç elde edildiği söylenebilir.
Hastaların endoskopi sonucu aldıkları tanılar incelendiğinde sadece 48 (\% 13,9) hastanın normal endoskopi sonucu olduğu, 23 hastaya $(\% \quad 6,3)$ çeşitli nedenlerle endoskopi yapılamadığı geri kalan hastalarda ise çoğunlukla birden fazla lezyonun beraber bulunduğu görülmüştür. Ülkemizde NVÜGK en sık nedenleri peptik ülser hastalığı ve eroziv gastroduodenittir ${ }^{14}$. Endoskopik tanılar arasında çalışmamızda en çok sırasıyla 145 hastada (\% 42,0) duodenal ülser, 125 hastada (\% 36,2) gastrit ve 105 hastada $(\%$ 30,4) mide ülseri tespit edilmiş olup literatürde görüldüğü gibi peptik ülser hastalığı en sık neden olarak karşımıza çıkmaktadır.

Endoskopi sonucu Forrest Ia, Ib, IIa ve hemodinamisi bozuk veya kanamanın devam ettiği düşünülen Forrest IIb ülserlere endoskopik tedavi önerilmektedir, Forrest IIc ve III ülserlere endoskopik tedavinin yararı gösterilmemiştir. Cander ve arkadaşları peptik ülser kanamalı hastalarda en sık Forrest III ülser \% 70 oranında tespit etmiş olup bizim çalışmamızda da \% 53,9 ile Forrest III en sik rastladığımız ülserdir ${ }^{15}$. Chuan ve arkadaşları yaptıkları çalışmada transfüzyon ihtiyac1, cerrahi veya endoskopik müdahale gerekliliği olan hastaları yüksek riskli olarak tanımlayarak PreRS'nun yeterliliğini değerlendirmiş ve bunun sonucunda PreRS ile 246 hastanın 220'si saptanmıştır ${ }^{16}$. Aynı şekilde çalışmamızda PreRS yüksek risk olan grupta yoğun bakıma yatış ve acilde exitus oranı PreRS düşük risk olan gruptan anlamlı $(\mathrm{p}<$ $0,05)$ olarak daha yüksek bulgulandı. Tham ve arkadaşları tarafından yapılan NVÜGK olan hastaların PreRS ile komplikasyon ve kan transfüzyonu ihtiyacının değerlendirildiği bir çalışmada ise endoskopi olmadan hesaplanan klinik (preendoskopik) Rockall skorunun düşük riskli hastaların belirlenip acil endoskopi ihtiyacını azaltmaya yönelik faydalı bir prognostik faktör olduğu ortaya konmuştur ${ }^{17}$.

Diğer taraftan çalışmamız sonucu PreRS düşük ve yüksek olan grupta cerrahi geçirme oranı, yatış günü, yatışta exitus oranı anlamlı $(\mathrm{p}>0,05)$ farklılık göstermedi ve PreRS düşük ve yüksek olan grupta tekrar kanama oranı anlamlı $(\mathrm{p}>0,05)$ farklılık saptanmadi. Custodio ve arkadaşları tarafindan NVÜGK olan hastalarda yapılan prospektif çalışmada PreRS'nun komplikasyonları ve tekrar müdahale gereksinimini belirlemede yetersiz kaldı $\breve{g}_{1}$ gösterilmiştir ${ }^{18}$. Meltzer ve arkadaşları ile Johnston ve arkadaşları tarafından yapılan çalışmalarda da PreRS'nun düşük riskli hastaları güvenilir bir şekilde bulma konusunda yetersiz olduğu öne sürülmüştür ${ }^{19,20}$.

Sonuç olarak, NVÜGK ile acil servise başvuran hastalarda risk sinıflaması yapılmasında PreRS kısıtlılıkları olmasına karşın klinisyene yardımcı olabilirken, hastaların klinik seyrinin öngörülmesinde yeterli fayda sağlamayabileceği söylenebilir.

\section{Çıkar çatışması}

Tüm yazarlar çıkar çatışması olmadığını beyan eder. 


\section{Phnx Med J. November, Volume 1 No 1}

\section{KAYNAKLAR}

1. Lewis JD, Bilker WB, Brensinger C, Farrar JT, Strom BL. Hospitalization and mortality rates from peptic ulcer disease and GI bleeding in the 1990s: Relationship to sales of nonsteroidal anti-inflammatory drugs and acid suppression medications. Am J Gastroenterol 2002; 97:2540-2549.

2. Marx AJ, Hockberger SR, Walls MR. Rosen's Emergency Medicine. 8th Ed., Philadelphia: Saunders, an imprint of Elsevier Inc, 2014. :248-253.

3. Gilbert DA. Epidemiology of upper gastrointestinal bleeding. Gastrointest Endosc 1990; 36:8-13.

4. Longstreth GF, Feitelberg SP. Outpatient care of selected patients with acute non-variceal upper gastrointestinal haemorrhage. Lancet 1995; 345:108-111.

5. Ferguson CB, Mitchell RM. Nonvariceal upper gastrointestinal bleeding: standard and new treatment. Gastroenterol Clin North Am 2005; 34:607-621.

6. Rockall TA, Logan RF, Devlin HB, Northfield TC. Risk assessment after acute upper gastrointestinal haemorrhage. Gut 1996; 38:316321.

7. Ferhat İÇME, et all, Analysis Of Endoscopic And Demographic Data Of The Patients Admitted To The Emergency Department With Non-Variceal Upper Gastrointestinal Bleeding, Turkish Medical Journal 2011:5(1)

8. Hamoui N, Docherty SD, Crookes PF. Gastrointestinal hemorrhage: is the surgeon obsolete. EmergMed Clin North Am 2003; 21(4):10171056.

9. Dicu D, Pop F, Ionescu D, et al. Comparison of risk scoring systems in predicting clinical outcome at upper gastrointestinal bleeding patients in an emergency unit. AJEM 2013; 31: 94-99.

10. Worthley DL, Fraser RJ. Management of acute bleeding in the upper gastrointestinal tract. Aust Prescr 2005; 28:62-66.

11. Işı et al. Comparison of some of the scoring systems and mean platelet volume in the prediction of mortality in patients admitted to the emergency department with upper gastrointestinal bleeding AbantMed J 2014;3(3):242-247.

12. Feldman M, Friedman LS, Sleisenger MH. Sleisenger \& Fordtran’s Gastrointestinal and Liver Disease: pathophysiology, diagnosis, management. 7th ed., Philadelphia:Saunders:2002.

13. Chen IC, Hung MS, Chiu TF, et al. Risk scoring systems to predict need for clinical intervention for patients with nonvariceal upper gastrointestinal tract bleeding. AJEM 2007; 25:774-779.

14. Ginsberg GG, Gostout CJ, Kochman ML, Norton ID. Clinical gastrointestinal endoscopy. 2nd Ed. Philadelphia: Saunders, an imprint of Elsevier Inc, 2012: 128-144.

15. Cander B, Ertekin B, Kara H, Gül M, Dündar D, Koçak S. Acil Servise Gastrointestinal Kanama İle Başvuran Hastalarda Hastane Yatı̧ Süresini Etkileyen Faktörler. Fırat Tip Dergisi 2011; 16: 54-56.

16. I-Chuan Chen et al. Risk scoring systems to predict need for clinical intervention for patients with nonvariceal upper gastrointestinal tract bleeding. American Journal of Emergency Medicine 2007; 25:774-779.

17. Tham TC, James C, Kelly M. Predicting outcome of acute non-variceal upper gastrointestinal haemorrhage without endoscopy using the clinical Rockall score. Postgrad Med J 2006 Nov;82(973):757-9.

18. Custodio LJ, Garcia MC, Kibune NC, et al. Performance of the Rockall scoring system in predicting the need for intervention and outcomes in patients with nonvariceal upper gastrointestinal bleeding in a Brazilian setting: a prospective study. Digestion 2013;88(4):252-

19. Meltzer AC, Burnett S, Pinchbeck C, et al. Pre-endoscopic Rockall and Blatchford scores to identify which emergency department patients with suspected gastrointestinal bleed do not need endoscopic hemostasis. J Emerg Med 2013 Jun;44(6):1083-7

20. Johnston MR, Murray IA, Schultz M, et al. Does preendoscopy Rockall score safely identify low risk patients following upper gastrointestinal haemorrhage? Gastroenterol Res Pract 2015;2015:410702. 